\title{
DER FRONBOTE
}

\section{IM MITTELALTER}

NACH DEM SACHSENSPIEGEL UND DEN VERWAND'IEN RECHTSQUELLEN.

EIN BEITRAG ZUR DEUTSCHEN RECHTSGESCHICHTE

VON

DR. JUR. CHRISTIAN ECKERT.

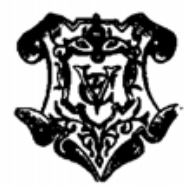

LEIPZIG,

VERLAG VON VEIT \& COMP.

1897. 
Druck von Metzger \& Wittig in Leipzig. 